\title{
Article \\ Comparison of Indoor Radon Reduction Effects Based on Apartment Housing Ventilation Methods
}

\author{
Jiwon Choi ${ }^{1}{ }^{\mathbb{C}}$, Hyongjin Hong ${ }^{1}{ }^{\mathbb{D}}$, Jeongsub Lee ${ }^{2}$, Seonhong Kim ${ }^{2}$, Gahyun Kim ${ }^{2}$, Boram Park ${ }^{2}$, \\ Eun-Min Cho ${ }^{1,3}$ and Cheolmin Lee ${ }^{1,3, * \mathbb{D}}$
}

Citation: Choi, J.; Hong, H.; Lee, J.; Kim, S.; Kim, G.; Park, B.; Cho, E.-M.; Lee, C. Comparison of Indoor Radon Reduction Effects Based on Apartment Housing Ventilation Methods. Atmosphere 2022, 13, 204. https://doi.org/10.3390/ atmos13020204

Academic Editors: Ashok Kumar

Received: 17 December 2021

Accepted: 23 January 2022

Published: 27 January 2022

Publisher's Note: MDPI stays neutral with regard to jurisdictional claims in published maps and institutional affiliations.

Copyright: (c) 2022 by the authors. Licensee MDPI, Basel, Switzerland. This article is an open access article distributed under the terms and conditions of the Creative Commons Attribution (CC BY) license (https:// creativecommons.org/licenses/by/ $4.0 /)$.
1 Department of Environmental Chemical Engineering, Seokyeong University, Seoul 02713, Korea; cjw101304@naver.com (J.C.); hongdonn01@skuniv.ac.kr (H.H.); choeunmin@hanmail.net (E.-M.C.)

2 Indoor Environment and Noise Research Division, National Institute of Environmental Research, Incheon 22689, Korea; ljsrex@korea.kr (J.L.); seonkim19@korea.kr (S.K.); gahyun0524@korea.kr (G.K.); brpark01@korea.kr (B.P.)

3 Department of Nano, Chemical \& Biological Engineering, Seokyeong University, Seoul 02713, Korea

* Correspondence: cheolmin@skuniv.ac.kr; Tel.: +82-0-2074-0409

\begin{abstract}
A lack of ventilation in multi-unit dwellings can affect human health adversely owing to accumulated radon gases; therefore, developing immediate and effective methods to reduce radon gas in indoor living environments is urgently needed. Therefore, this study conducted a basic research study to develop ventilation guidelines for radon through assessments of various ventilation strategies on indoor radon concentration in multiple-unit dwellings, a typical residential type in Korea. Radon measurement was conducted in November 2020 using RAD 7 Radon Detector (Durridge Co., Billerica, MA, USA) for living rooms and rooms of an apartment located in Uijeongbu, Gyeonggi-do, Korea. The radon reduction effect according to the ventilation conditions per hour was compared and evaluated by performing seven natural ventilation scenarios through opening and closing windows leading to the outside and three types of mechanical ventilation with high, middle, and low operating intensity. The concentration ratio $\left(C_{r}\right)$ was estimated to present the indoor radon increase/decrease ratio. Among the natural ventilation scenarios, Case 3 had the highest radon reduction rate in the living room and Case 1 in the room, and Case 2 using natural ventilation equipment showed the lowest reduction rate in both the room and the living room. When ventilated by mechanical ventilation conditions, the radon reduction rate $\left(\mathrm{P}_{\mathrm{r}}\right)$ was $70 \%$ or less under all conditions. Under the natural ventilation measurement condition, when every doors and windows was opened, it showed an effective ventilation in a short time. With high mechanical ventilation, the radon reduction effect in a relatively large space was better. Additionally, with middle and low mechanical ventilation, the reduction effect seems to be good in a relatively narrow space.
\end{abstract}

Keywords: indoor air quality; mitigation; apartment; radon; ventilation

\section{Introduction}

Radon is a naturally occurring radionuclide that is released into the atmosphere as a gas during the decay process of its parent nuclide uranium $\left({ }^{238} \mathrm{U}\right)$ in the ground. Radon gas is colorless, odorless, and difficult to directly identify, thereby posing a serious health risk in indoor environments, such as homes [1-4]. It has a half-life of approximately 3.8 days, and when it enters an indoor space in a chemically inert gaseous state, the human body can be easily exposed to it via respiration [5-8]. Radon from various sources has been reported to be deposited in the lungs via respiration and can cause damage to the cells owing to an internal exposure to radiation [9]. According to the Environmental Protection Agency (EPA) in the United States, approximately 21,000 people die annually from lung cancer induced by radon, and they emphasized that, after smoking, the second most common cause of death from lung cancer is radon exposure [10]. The International Agency for Research on Cancer (IARC, France) designated radon as a class 1 carcinogen in terms of harmfulness to 
human health and body [2]. Radon gas is mainly generated from the soil where buildings are constructed, from where it partially flows into the indoors through gaps and cracks in buildings. In addition, radon gas generated from building materials in indoor spaces is also known to be a major potential source of radon contamination [11-15].

Keller et al. (2001) verified the possibility of radon exhalation from building materials in indoor spaces. However, because exhalation may be low owing to individual effects of building materials such as the degree of sealing and airtightness, as well as structural differences, it is necessary to verify radon concentration by direct investigations in actual indoor spaces [16]. Concentrated evaluations of specific building materials are necessary for radon exhalation from building materials; however, there have been instances in which radon exhalation rates 5 to 9 times higher were investigated depending on the structure of the apartment housings and the influence of the building materials, and building materials directly exposed to the interior have been identified as factors that can determine indoor radon concentrations [17]. In houses with successful air exchange, radon exhalation from building materials do not significantly affect the indoor air quality [18]. Meanwhile, the absence of ventilation can cause health hazards owing to the accumulation of radon gas, even in environments with low exposure to radon [19].

Therefore, various environmental parameters, such as indoor decompression level, meteorological condition, ground and building characteristics, air exchange rate, and ventilation type can influence both the radon influx into a building and the associated indoor radon concentration. In addition, these parameters can affect indoor radon dilution, and regardless of the use of a building, proper ventilation is crucial for radon reduction [20]. Currently, research in South Korea on national standards such as the guidelines for the management of radon reduction in apartment housings via ventilation and other means has commenced; however, available fundamental data are insufficient. Hence, prompt and reliable reduction measures are required for indoor living environments.

This study was performed to evaluate various effects of indoor radon ventilation in apartment housings, which is the most common type of residence in South Korea, and to provide baseline data for the development of South Korean ventilation guidelines. This study was conducted in an actual living environment to provide baseline data for radon research, which is subject to uncertainties triggered by the effects of various parameters.

\section{Methods}

\subsection{Study Target and Duration}

Radon was measured for 11 days from 16 November to 26 November 2020, in a household living in an apartment located in Nakyang-dong, Uijeongbu-si, Gyeonggi-do, Korea. An apartment constructed in 2015 was selected to minimize the effects of air infiltration due to aging and cracks in building materials. The measurement locations include the living room, which was the basic location indicated in the official indoor airquality test standard announced by the Ministry of Environment (Korea), and the farthest room from the living room to compare the radon concentration. The living room had a glass window that could be opened from both sides, and the size of both windows was $85 \mathrm{~cm} \times 220 \mathrm{~cm}$. The window in the kitchen connected to the living room was installed to ventilate the kitchen while cooking. It is positioned opposite the window in the living room with dimensions $60 \mathrm{~cm} \times 120 \mathrm{~cm}$. The windows in the room and the balcony window were $90 \mathrm{~cm} \times 235 \mathrm{~cm}$ and $90 \mathrm{~cm} \times 220 \mathrm{~cm}$, respectively. Measurements were carried in the household where radon could be measured according to the planned ventilation scenarios of the natural ventilation with the condition of having a resident and using the air-conditioning ventilation system. The detailed features of the studied household in this study, including the floor, area, etc., are provided in Table 1. 
Table 1. Study target household structure and characteristics.

\begin{tabular}{cc}
\hline Location & $\begin{array}{c}\text { Nakyang-dong, Uijeongbu-si, } \\
\text { Gyeonggi-do, Korea }\end{array}$ \\
\hline Household floor & 12th floor \\
\hline Apartment type & $\begin{array}{c}\text { Tower-shaped apartment } \\
\text { Form }\end{array}$ \\
\hline Area & $\begin{array}{c}\text { Room: } 11.5 \mathrm{~m}^{2} \\
\text { bathrooms }\end{array}$ \\
\hline Volume & Living Room: $21.4 \mathrm{~m}^{2}$ \\
\hline Rechanical ventilation & Energy recovery ventilator system \\
\hline
\end{tabular}

\subsection{Radon Measurement Device}

The RAD 7 Radon Detector (Durridge Co., Billerica, MA, USA), a continuous radon measurement device, was used in the living room and the farthest room from the living room in the same manner to minimize the deviation between the measurement devices. They were installed in the center of the spaces at $1.2-1.5 \mathrm{~m}$ from the ground, such that they represent the measurement spaces according to the official indoor air-quality test standard. The average concentration of radon per unit time $\left(\mathrm{Bq} \mathrm{m}^{-3}\right)$ measured after $3 \mathrm{~h}$ was adopted, after eliminating the possible influence of radon remaining in the device during the first $3 \mathrm{~h}$ of measurement.

\subsection{Measurement Method}

To study the efficiency of radon reduction by ventilation types in the room and living room, the rooms were sealed for about $4 \mathrm{~h}$ or more, according to the official indoor air-quality test standard, such that the radon concentration could increase sufficiently, which was followed by ventilation for $6 \mathrm{~h}$, according to the ventilation types. During the measurements, the entrances, exits, windows, toilets, etc., of the rooms not subject to measurement remained closed.

The variations in radon concentration according to the ventilation types were measured for natural and mechanical ventilation. Natural ventilation was adopted in the opening and closing of windows and doors leading to the outside, hence the natural ventilation system used air conditioning structures installed in windows. The mechanical ventilation measurement was classified into high, middle, and low intensities, based on the Enforcement Decree of the Building Act No. 2013-23 of the Ministry of Land, Infrastructure, and Transport (Korea).

The natural ventilation case proceeded with seven varying conditions, from Cases 1 to 7, as presented in Figure 1. In Case 1, all the windows in the living room and kitchen were open, and the room window and door connected to the living room were open for ventilation. In Case 2, the door connecting the living room to the room was closed during the natural ventilation by the system installed in the window. In Case 3, only the living room window was opened, while the room door, room window, and kitchen window were closed. In Case 4, the door between the living room and the room was closed, the window in the living room was closed, and the kitchen and room windows were opened for ventilation. In Case 5, the room door and window were closed, the kitchen window was open, and only one of the two living room windows was open for ventilation. In Case 6 , the room door and window and the kitchen window were closed, and only one of the two living room windows was open for ventilation. In Case 7, all the windows in the living room and kitchen were closed; however, the door and window in the room were open for ventilation. 


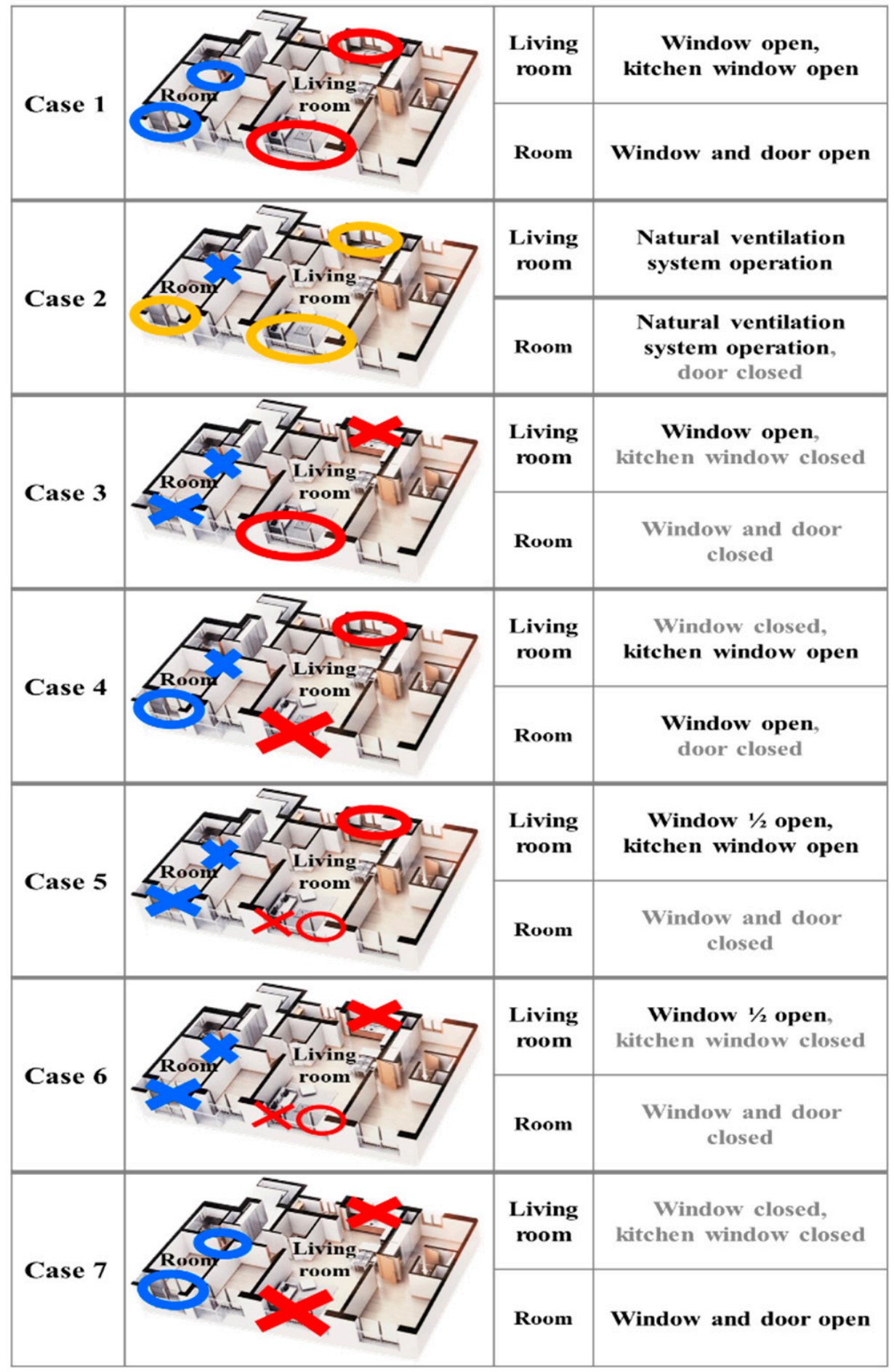

Figure 1. Natural ventilation type scenarios.

Mechanical ventilation was performed using the air-conditioning system under three conditions: high, middle, and low intensities. The door between the living room and the room remained closed during mechanical ventilation in each space.

The measurement device installation locations, window locations, mechanical/natural ventilation systems, and natural ventilation locations from this study are presented in Figure 2. 


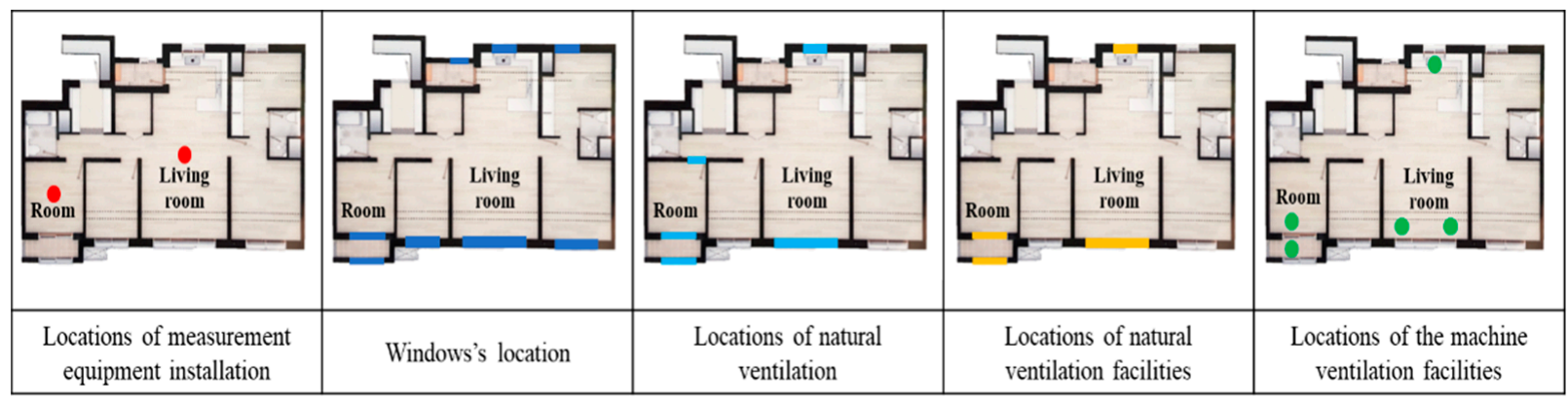

Figure 2. Locations of measurement device installation, windows, mechanical/natural ventilation systems, and natural ventilation executions.

\subsection{Analysis Method}

The concentration ratio $\left(C_{r}\right)$ was calculated using Equation (1), by dividing the measured radon concentration by the initial radon concentration, to examine the reduction in indoor radon concentration according to the ventilation type [21]. In addition, the radon reduction rate $\left(\mathrm{P}_{\mathrm{r}}\right)$ was calculated with Equation (2), using the concentrations before and after ventilation.

The calculation equations adopted in this study are expressed as follows.

$$
\begin{gathered}
\mathrm{C}_{\mathrm{r}}=\frac{\mathrm{C}}{\mathrm{C}_{0}} \\
\mathrm{P}_{\mathrm{r}}=\frac{\mathrm{C}_{0}-\mathrm{C}_{\min }}{\mathrm{C}_{0}}
\end{gathered}
$$

where $C_{r}$ denotes the radon concentration ratio, $C$ denotes radon concentration during ventilation $\left(\mathrm{Bq} \mathrm{m}^{-3}\right), \mathrm{C}_{0}$ denotes initial radon concentration at the beginning of ventilation $\left(\mathrm{Bq} \mathrm{m}{ }^{-3}\right), \mathrm{P}_{\mathrm{r}}$ denotes radon reduction rate, and $\mathrm{C}_{\mathrm{min}}$ denotes minimum radon concentration during ventilation.

\section{Results}

\subsection{Radon Reduction from Each Natural Ventilation Conditions}

Natural ventilation was performed according to each scenario from Cases 1 to 7 , and the results obtained from the comparison of indoor radon concentrations are presented with the recommended standards $148 \mathrm{~Bq} / \mathrm{m}^{3}$ by Ministry of Environment, Korea (Figure 3). $\mathrm{C}_{\mathrm{r}}$ was calculated to identify the indoor radon increase/decrease ratios according to each scenario (Figure 4), while $C_{0}$ and $C_{\min }$ were demonstrated to identify the radon reduction rates according to each scenario (Figure 5 and Table 2).

In Case 1, after natural ventilation, radon concentration decreased from $134.73 \mathrm{~Bq} \mathrm{~m}^{-3}$ to $14.71 \mathrm{~Bq} \mathrm{~m}^{-3}$ in the living room and from $163.29 \mathrm{~Bq} \mathrm{~m}^{-3}$ to $10.83 \mathrm{~Bq} \mathrm{~m}^{-3}$ in the room, with high reduction rates of $89.08 \%$ and $93.37 \%$, respectively. In Case 2, where the natural ventilation system equipment was operated, the decrease in radon concentration was inconsistent, and the concentration was higher than the standard value of $148 \mathrm{~Bq} \mathrm{~m}^{-3}$ during ventilation. After $1 \mathrm{~h}$ of ventilation in the living room and $2 \mathrm{~h}$ in the room, low reduction rates of $20.27 \%$ and $11.62 \%$ were observed, respectively. In addition, the concentration ratio increased to 1.46 and 1.19 in the living room after $4 \mathrm{~h}$ of ventilation and in the room after $3 \mathrm{~h}$ of ventilation, respectively. In Case 3, the concentration in the living room with direct ventilation decreased from $86.90 \mathrm{~Bq} \mathrm{~m}^{-3}$ at the onset of ventilation to $4.01 \mathrm{~Bq} \mathrm{~m}^{-3}$ after $5 \mathrm{~h}$, thereby exhibiting a high reduction rate of $95.38 \%$. Here, the $C_{r}$ value was 0.05 , which was the lowest value among the ventilation scenarios in the living room and the room. Meanwhile, in the room without direct ventilation, the concentration after ventilation reduced from $140.09 \mathrm{~Bq} \mathrm{~m}^{-3}$ to $88.29 \mathrm{~Bq} \mathrm{~m}^{-3}$, which was a relatively low reduction at $36.98 \%$. In Case 4 , where independent ventilations proceeded with the door connecting the 
living room and the room closed, the reduction rates were $64.54 \%$ and $90.42 \%$ in the living room and the room, respectively. In Case 5 where ventilation proceeded solely in the living room, the living room exhibited a $90.53 \%$ reduction from $127.01 \mathrm{~Bq} \mathrm{~m}^{-3}$ to $12.03 \mathrm{~Bq} \mathrm{~m}^{-3}$ after $3 \mathrm{~h}$ of ventilation, while the room exhibited a $59.39 \%$ reduction. Similarly, in Case 6 , where ventilation solely proceeded in the living room, the reduction rate in the living room was $84.04 \%$ from $92.25 \mathrm{~Bq} \mathrm{~m}^{-3}$ to $14.72 \mathrm{~Bq} \mathrm{~m}^{-3}$, while that of the room was $46.72 \%$. In Case 6, the $C_{r}$ value of the room was 1.09 after $1 \mathrm{~h}$ from the onset of ventilation, the radon concentration decreased after a partial increase, and the initial concentration of $198.49 \mathrm{~Bq} \mathrm{~m}^{-3}$ decreased to $111.48 \mathrm{~Bq} \mathrm{~m}^{-3}$ after a 3-h ventilation, which was below the standard value. In Case 7, which was ventilated by opening only the door and window of the room while leaving the window in the living room completely closed, the reduction rate was $92.38 \%$ in the living room and $93.13 \%$ in the room, both exhibiting high reduction rates. The concentration in the room after $1 \mathrm{~h}$ of ventilation decreased from $157.63 \mathrm{~Bq} \mathrm{~m}^{-3}$ to $73.15 \mathrm{~Bq} \mathrm{~m}^{-3}$, which was confirmed as equal to or below the standard value.

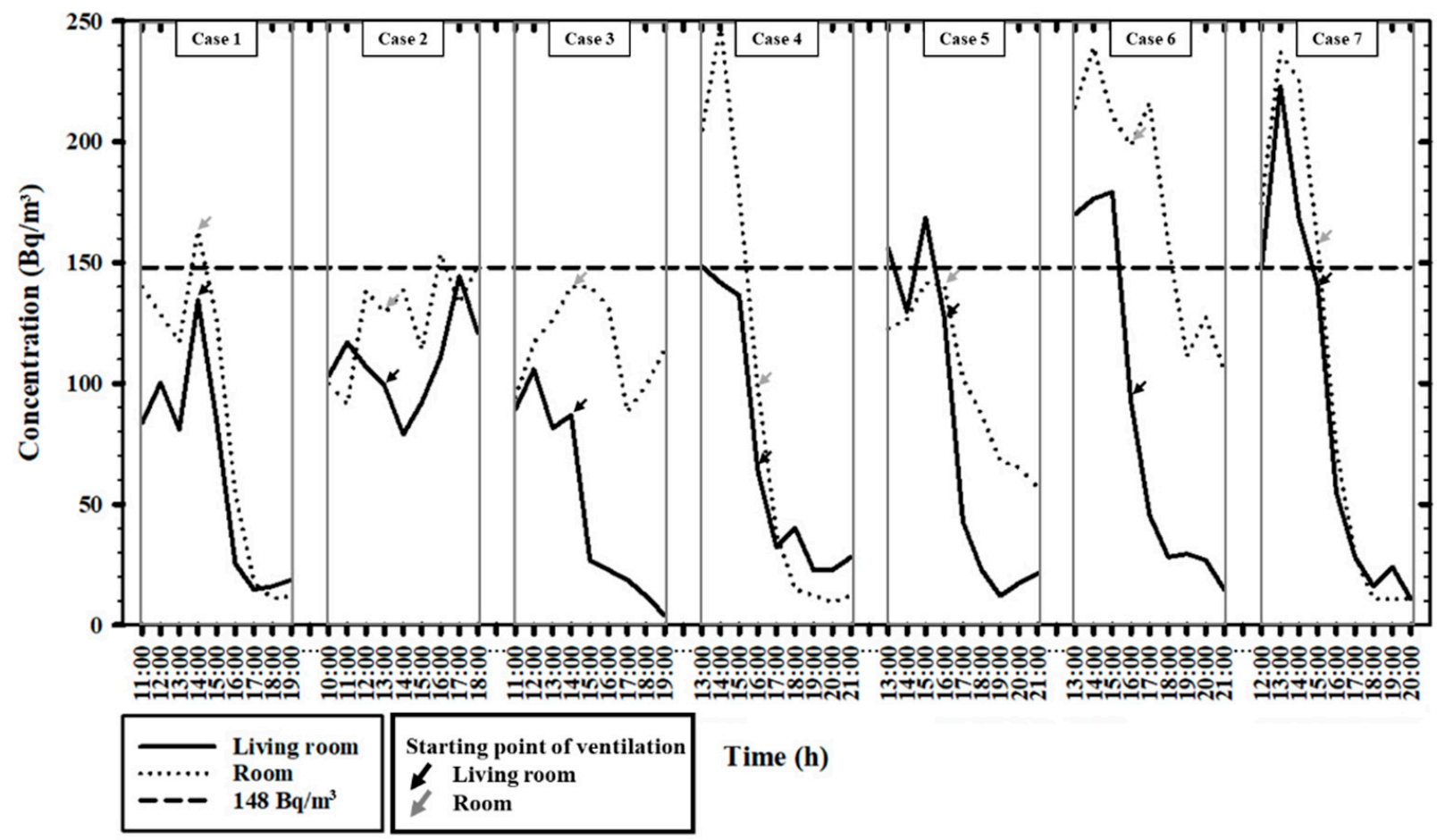

Figure 3. Radon concentration from each natural ventilation scenario.

In Cases 3, 5, and 6, when all the doors and windows of the room were closed, and only the ventilation conditions in the living room were differentiated, it was confirmed that the radon concentrations in the room and living room reduced simultaneously. However, the reduction rates were relatively low, $60 \%$ or less. In the living room, the highest concentration rate was observed in Case 3, followed by Cases 5 and 6 . In Case 4, where ventilations were conducted in independent spaces, the reduction rates were $64.54 \%$ and $90.42 \%$ in the living room and room, respectively, thereby indicating a higher reduction rate in the relatively smaller space.

Radon concentrations decreased to low levels of $4.01-22.76 \mathrm{~Bq} \mathrm{~m}^{-3}$ after ventilation in the remaining scenarios, excluding the rooms in Cases 3, 5, and 6, where windows and rooms were not opened for ventilation, and in Case 2 where the natural ventilation system was employed. 

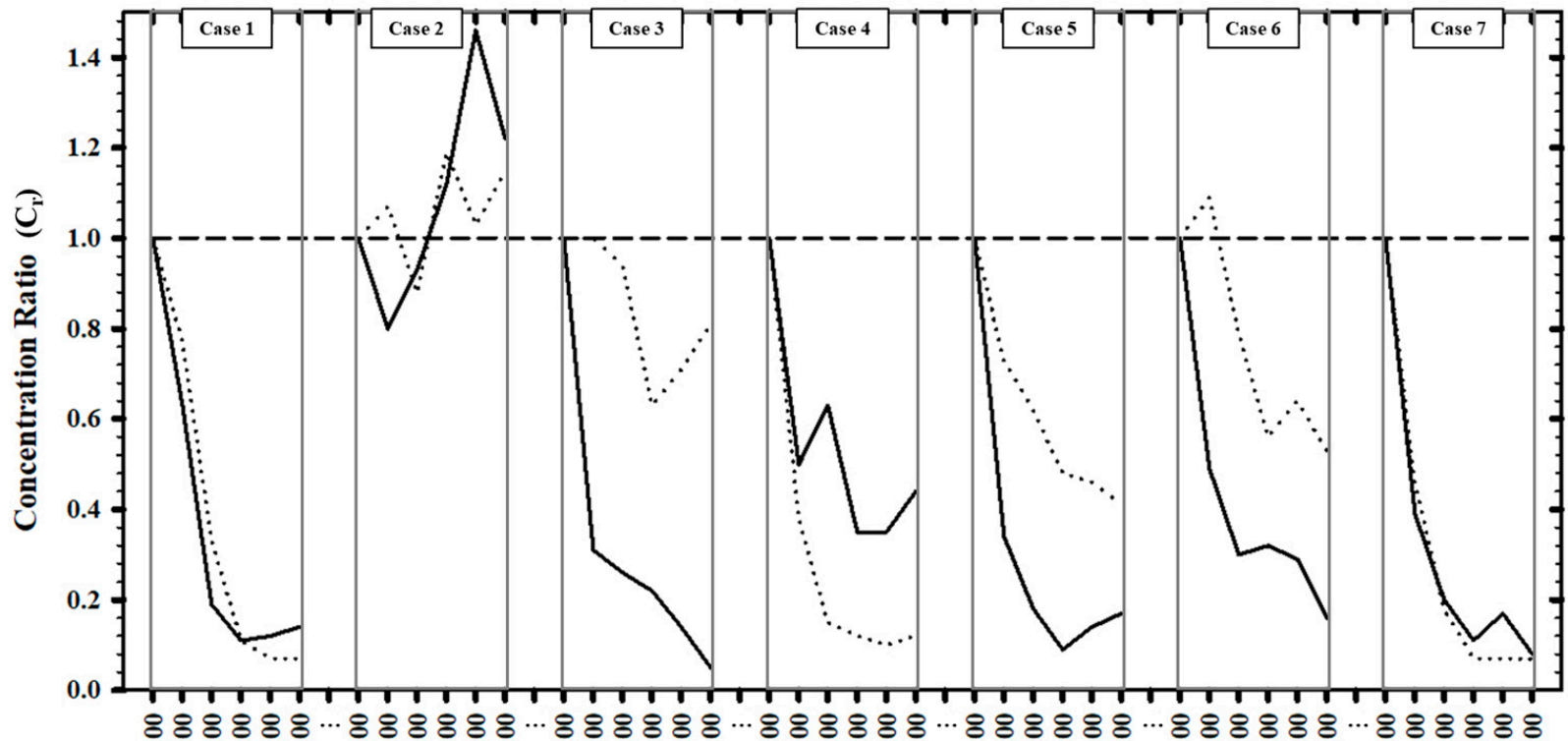

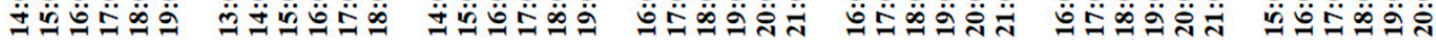

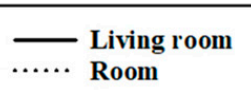

Time (h)

Figure 4. Radon concentration ratio from each natural ventilation scenario.
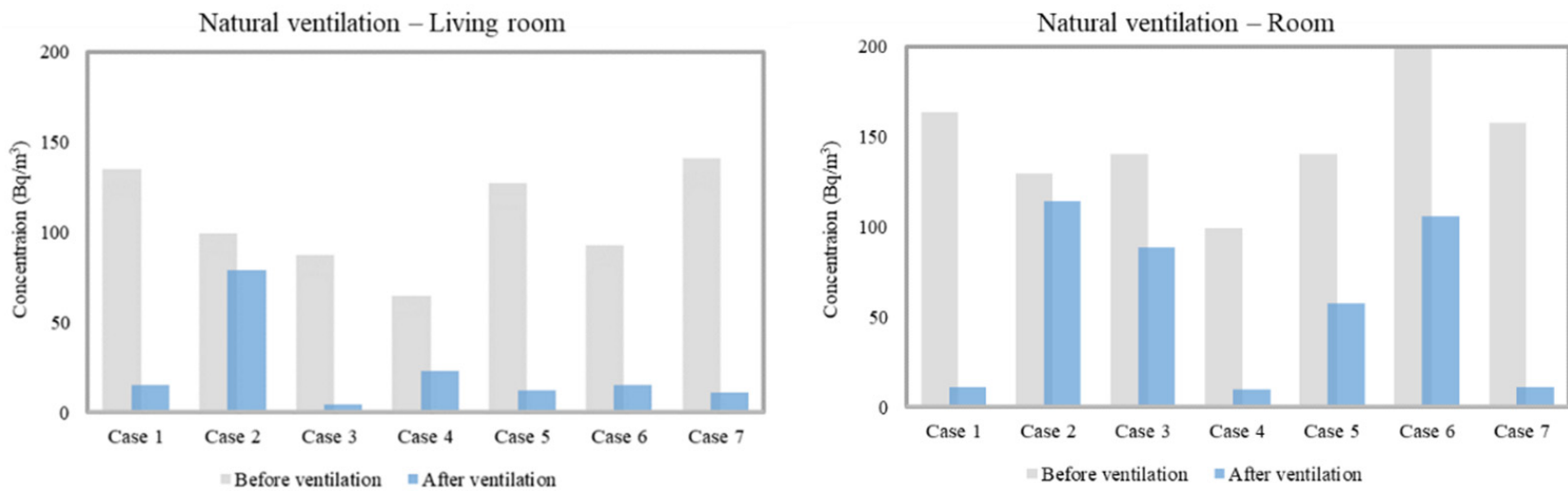

Figure 5. Radon reduction concentration from each natural ventilation scenario.

Table 2. Radon reduction rate $\left(\mathrm{P}_{\mathrm{r}}\right)$ from each natural ventilation scenario.

\begin{tabular}{|c|c|c|c|c|c|c|}
\hline & \multicolumn{3}{|c|}{ Living Room } & \multicolumn{3}{|c|}{ Room } \\
\hline & $\mathrm{C}_{0}\left(\mathrm{~Bq} \mathrm{~m}^{-3}\right)$ & $\mathrm{C}_{\min }\left(\mathrm{Bq} \mathrm{m}^{-3}\right)$ & $P_{r}(\%)$ & $\mathrm{C}_{0}\left(\mathrm{~Bq} \mathrm{~m}^{-3}\right)$ & $\mathrm{C}_{\min }\left(\mathrm{Bq} \mathrm{m}^{-3}\right)$ & $P_{r}(\%)$ \\
\hline Case 1 & 134.73 & 14.71 & 89.08 & 163.29 & 10.83 & 93.37 \\
\hline Case 2 & 98.93 & 78.88 & 20.27 & 129.15 & 114.15 & 11.62 \\
\hline Case 3 & 86.90 & 4.01 & 95.38 & 140.09 & 88.29 & 36.98 \\
\hline Case 4 & 64.17 & 22.76 & 64.54 & 98.89 & 9.47 & 90.42 \\
\hline Case 5 & 127.01 & 12.03 & 90.53 & 140.40 & 57.02 & 59.39 \\
\hline Case 6 & 92.25 & 14.72 & 84.04 & 198.49 & 105.76 & 46.72 \\
\hline Case 7 & 140.44 & 10.71 & 92.38 & 157.63 & 10.83 & 93.13 \\
\hline
\end{tabular}




\subsection{Radon Reduction from Mechanical Ventilation Conditions}

The results obtained from the comparison of indoor radon concentrations from each mechanical ventilation condition, which were categorized into high, middle, and low operational intensities, are provided natural ventilation was performed according to each scenario from Cases 1 to 7 , and the results obtained from the comparison of indoor radon concentrations are presented with the recommended standards $148 \mathrm{~Bq} / \mathrm{m}^{3}$ by Ministry of Environment, Korea (Figure 6). In addition, $\mathrm{C}_{\mathrm{r}}$ values were calculated to identify the indoor radon increase/decrease ratios (Figure 7), while $C_{0}$ and $C_{\min }$ values were presented to identify the radon reduction rates according to each scenario (Figure 8 and Table 3).

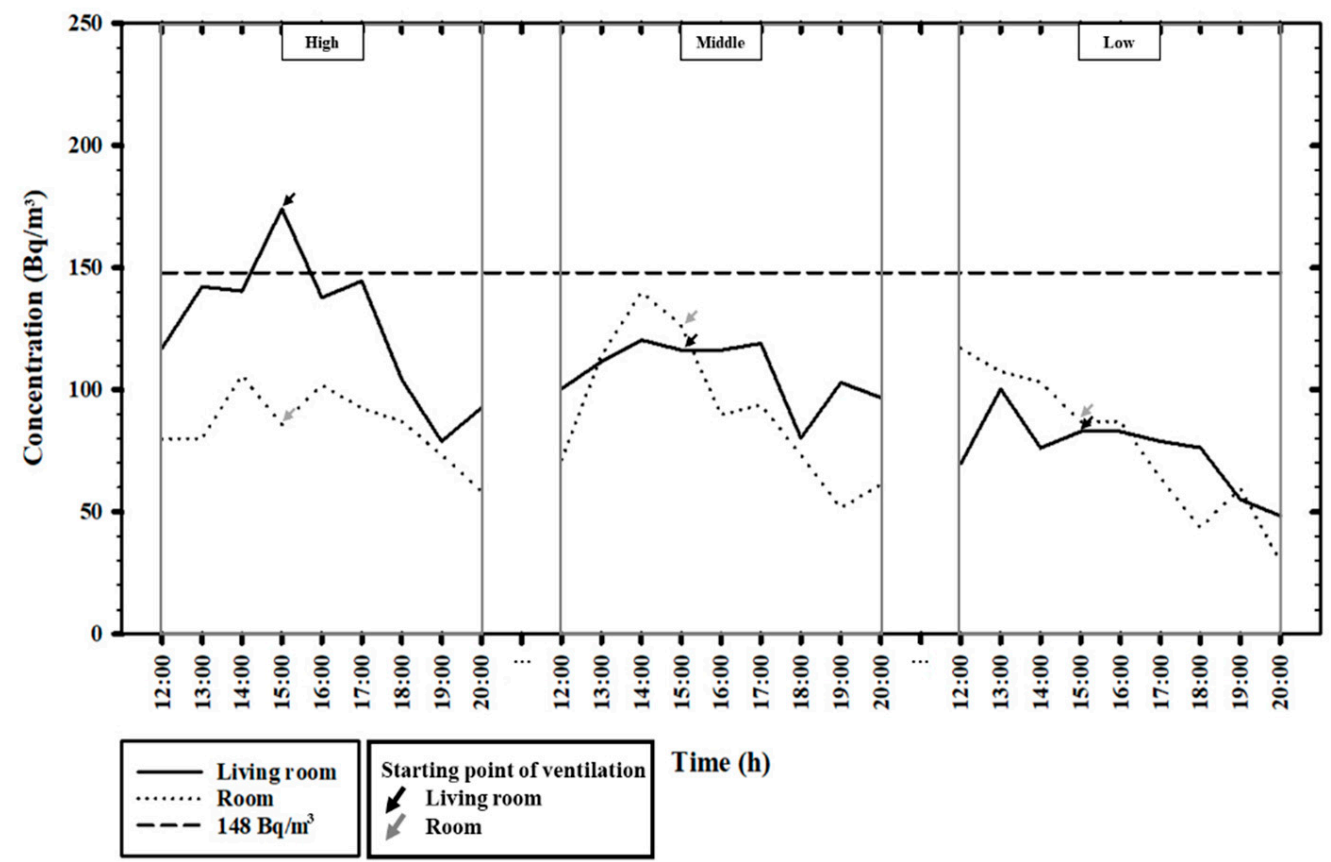

Figure 6. Radon concentrations from each mechanical ventilation operational conditions.

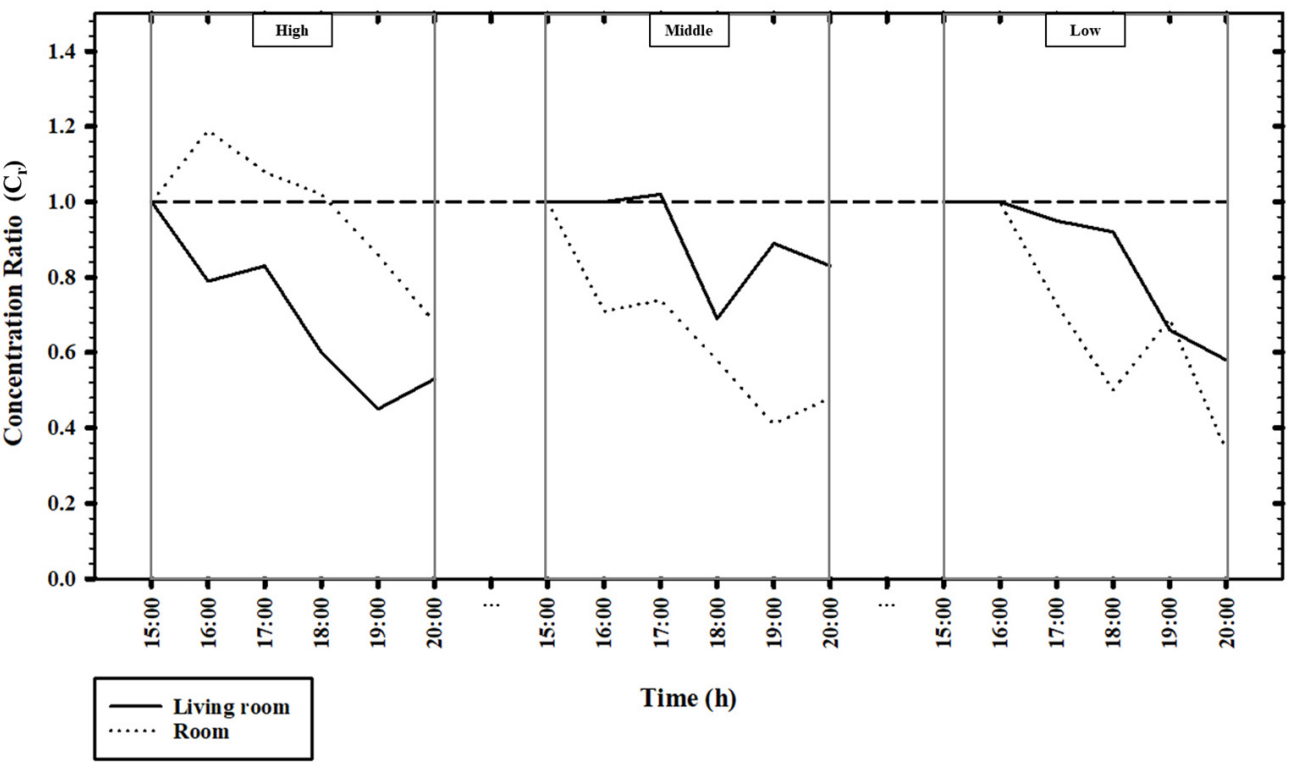

Figure 7. Radon concentration ratio from each mechanical ventilation operational condition. 

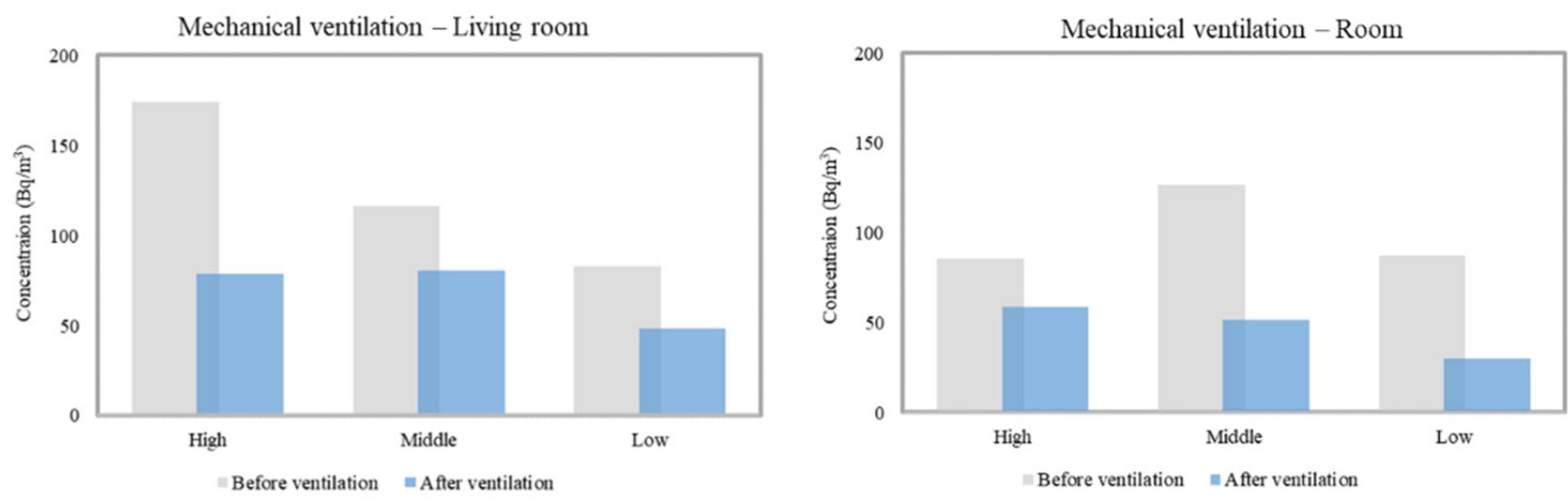

Figure 8. Radon reduction concentration from each mechanical ventilation operational condition.

Table 3. Radon reduction rate $\left(\mathrm{P}_{\mathrm{r}}\right)$ from each mechanical ventilation operational condition.

\begin{tabular}{|c|c|c|c|c|c|c|}
\hline & \multicolumn{3}{|c|}{ Living Room } & \multicolumn{3}{|c|}{ Room } \\
\hline & $\mathrm{C}_{0}\left(\mathrm{~Bq} \mathrm{~m}^{-3}\right)$ & $C_{\min }\left(\mathrm{Bq} \mathrm{m}^{-3}\right)$ & $P_{r}(\%)$ & $\mathrm{C}_{0}\left(\mathrm{~Bq} \mathrm{~m}^{-3}\right)$ & $C_{\min }\left(B \mathrm{~m}^{-3}\right)$ & $P_{r}(\%)$ \\
\hline High & 174.11 & 78.88 & 54.70 & 85.61 & 58.33 & 31.87 \\
\hline Middle & 116.31 & 80.22 & 31.03 & 126.38 & 51.61 & 59.16 \\
\hline Low & 82.89 & 48.37 & 41.65 & 86.93 & 29.86 & 65.66 \\
\hline
\end{tabular}

Before the high mechanical ventilation, the radon concentration in the living room was at $174.11 \mathrm{~Bq} \mathrm{~m}^{-3}$, which exceeded the standard value of $148 \mathrm{~Bq} \mathrm{~m}^{-3}$. After $1 \mathrm{~h}$ of ventilation, it was reduced to a value below the standard value, at a reduction rate of a $54.7 \%$. In the room, after the $C_{r}$ value increased to 1.19 after $1 \mathrm{~h}$ of ventilation, the concentration gradually decreased and exhibited a $31.87 \%$ reduction rate. In the middle mechanical ventilation condition, the radon concentration after $1 \mathrm{~h}$ in the living room had not changed from before the ventilation, which after the partial increase in concentration and the increase in $\mathrm{C}_{\mathrm{r}}$ to 1.02 after $2 \mathrm{~h}$ of ventilation exhibited a $31.03 \%$ reduction rate after $3 \mathrm{~h}$ of ventilation. The radon concentration in the room was reduced from $126.38 \mathrm{~Bq} \mathrm{~m}^{-3}$ to $51.61 \mathrm{~Bq} \mathrm{~m}^{-3}$ by $59.16 \%$. In the low mechanical ventilation condition, the living room and room exhibited reduction rates of $41.65 \%$ and $65.66 \%$, respectively, and the $C_{r}$ value was the lowest value at 0.34 among the living room and room ventilation conditions.

In the high mechanical ventilation condition, the reduction rate was higher in the living room than in the room; however, in the middle and low mechanical ventilation conditions, the reduction rate was higher in the room with a smaller area than the living room.

\section{Discussion}

In a household located on the 12th floor of a newly constructed apartment building, it could be considered that radon is commonly emitted from the soil in the housing facilities of the upper floors and the newly constructed buildings, and the influence of radon inflow through cracks in buildings is low indoors. However, in this study, it was verified to be at the standard value of $148 \mathrm{~Bq} \mathrm{~m}^{-3}$ or above, but without ventilation. Results obtained from a previous study results indicated that in a 2017 survey from the National Geographic Information Institute of the Ministry of Land, Infrastructure, and Transport, in certain areas of South Korea, the radon concentrations in apartments and multiunit housing in the form of apartment housing were determined to be at $148 \mathrm{~Bq} \mathrm{~m}^{-3}$ (or above) or approaching the standard value [22]. This implies that in the apartment housing, the most common residence type in South Korea, despite being on upper floors in newly constructed apartment, exposure to radon above the standard value is possible, which required suitable radon management by studies on indoor radon. The target household of this study was 
geologically located in the sedimentary rock zone and surrounded by Daebo granites and biotite granite zones. The radon from the indoor air of the target household was estimated to have been generated from the indoor building materials or the soil, which traveled through the pipes and infiltrated the upper floors.

In this study, the rooms were sealed for more than $4 \mathrm{~h}$ before the start of ventilation because the radon reduction effect of ventilation could be underestimated if the ventilation began when the room radon concentration was distributed at a low level during the measurements. In Case 1, under the natural ventilation measurement condition, high reduction rates of $89.08 \%$ and $93.37 \%$ were observed in the living room and the room, respectively, and it was confirmed that the radon concentration could be reliably reduced by opening all the windows in the living space. Furthermore, in Case 1, the radon concentration in the living room decreased to the lowest level within $3 \mathrm{~h}$ after the start of ventilation, thus indicating that the ventilation of the entire household, even for a short period, is effective for indoor radon management. However, in Case 2, the reduction rate of $20.27 \%$ and $11.62 \%$ in the living room and room, respectively, indicated that the radon concentration increased above the standard during ventilation. Based on this result, it was considered that the operating natural ventilation system equipment can support the redistribution of indoor air in the apartment housing; however, when used alone, it is difficult to control the indoor radon concentration via ventilation. Comparing the results of Cases 3, 5, and 6 , in which ventilation activities proceeded in the living room while the room windows remained closed, the reduction rates were $95.38 \%, 90.53 \%$, and $84.04 \%$, respectively, with higher reduction rates in the living room in the order of Cases 3,5, and 6. This indicated that the ventilation method of opening both the living room windows in Case 3 is more effective than the method of opening one of the windows in Case 6, and the bidirectional ventilation through the opposing window in Case 5 is more effective than the unidirectional ventilation in Case 6. In Case 4, where the room door was closed and independent ventilation proceeded in the living room and room, the reduction rate was as high as $90.42 \%$ in the room, while the living room exhibited a relatively low reduction rate of $64.54 \%$. In addition, a difference of $30.85 \%$ was observed, compared to the reduction rate of $95.38 \%$ in the living room of Case 3, which was ventilated with the room door closed. This implies that ventilation in a small space is more effective than in a large space, and the ventilation through a wide window is more effective than ventilation through a narrow window. In Case 6, the radon concentration in the room increased immediately after the beginning of ventilation and decreased $1 \mathrm{~h}$ later. The increase in concentration was considered to have originated from the temporary change in the current in the room, owing to the procession of ventilation in the living room, despite the absence of ventilation in the room, which affected the gaseous radon concentration. Although both Cases 1 and 7 exhibited high reduction rates, the lowest radon concentration appeared after 3 and $4 \mathrm{~h}$ in the living room and room of Case 1, and after 5 and $4 \mathrm{~h}$ in the living room and room of Case 7, respectively. This indicates that although the radon concentration in the living room can be controlled by ventilation in the room, it is more suitable to ventilate all spaces of the entire household for effective indoor radon control in a short time.

The investigation of the ventilation scenarios in the room indicated that Cases 1, 4, and 7, which were directly ventilated, all exhibited reduction efficiencies of $90 \%$ or above, at $93.37 \%, 90.42 \%$, and $93.13 \%$, respectively, while Cases 3, 5, and 6, which were affected by indirect ventilation in the living room through closed windows and doors and gaps in the doors, exhibited relatively low reduction efficiencies of $60 \%$ or below. The reduction of radon concentration in the room up to a certain level indicates that radon was reduced by indirect ventilation effects, even if the room door and window were closed; however, the reduction rate at $60 \%$ or below implies that effective indoor radon management could not be achieved without direct ventilation. In addition, in the three scenarios, the orders of the scenarios that exhibited high reduction rates in the living room did not match the order of the reduction rates in the room, thereby suggesting that the radon reduction in the unventilated room was more influenced by atmospheric pressure and other factors 
than the radon reduction effect in the living room. Therefore, it was considered that direct ventilation is more efficient for reliable reduction effects in the room with ventilation by opening the room windows or doors connected to the outside and living room, even though the room could be affected by the natural ventilation of the living room.

In the room under the high mechanical ventilation condition, the $C_{r}$ value was 1.19 for $1 \mathrm{~h}$ after the start of ventilation. The radon concentration increased and was followed by a gradual decrease, which was considered to have originated from a strong current change after mechanical ventilation, as radon was in a gaseous state. In the high mechanical ventilation condition, the reduction rate was higher in the living room than in the room, while in the middle and low mechanical ventilation conditions the rate was higher in the room than in the living room. The indoor radon concentration reduction was most effective at $54.70 \%$ with "high" mechanical ventilation in the living room; however, the reduction rate was $50 \%$ or below when operating under middle and low mechanical ventilation conditions. Proceeding ventilation with an intensity of high mechanical ventilation or above or mechanical ventilation in parallel with natural ventilation was considered efficient in predicting the radon reduction effect in the living room from mechanical ventilation alone. Meanwhile, the indoor radon concentration reduction with mechanical ventilation in the room was most efficient at $65.66 \%$ with the low mechanical ventilation, and a relatively high reduction efficiency was also observed from the middle mechanical ventilation at $59.16 \%$. However, a reduction rate lower than 50\% was observed from the high mechanical ventilation, thereby indicating that the low mechanical ventilation intensity is more effective than high intensity for radon management in narrow spaces. Therefore, it was determined that low mechanical ventilation intensity in narrow spaces and high mechanical ventilation intensity in wide spaces were effective for radon reduction.

In this study, based on various natural and mechanical ventilation conditions by the intensity of operation, various ventilation effects on radon in the indoor environment of an apartment housing, the most common type of residence in South Korea, were evaluated. Basic research was conducted to establish indoor ventilation guidelines via this evaluation. In addition, the study proceeded in an actual living environment with the condition of having residents, which was considered to sufficiently contribute to radon studies previously believed to have uncertainties regarding the influence of various environmental parameters.

\section{Conclusions}

In this study, basic research was conducted to develop guidelines for radon ventilation by evaluating various ventilation effects of indoor radon in apartment housings under various natural and mechanical ventilation conditions with different operational intensities. Accordingly, seven natural ventilation scenarios and three different mechanical ventilation operating conditions were investigated to compare and evaluate the radon reduction effects according to the ventilation operations per hour, with windows and doors that could be naturally ventilated, living room and room with natural ventilation, and mechanical ventilation system equipment as targets using the RAD 7 Radon Detector (Durridge Co., Billerica, MA, USA).

The results obtained from this study indicated that even in households on the upper floors of an apartment building, radon can accumulate at concentrations above the standard value in the absence of ventilation. Hence, appropriate radon management via ventilation is required.

Operating the natural ventilation system equipment can support the redistribution of the indoor air in an apartment house; however, controlling the indoor radon concentration by ventilation was challenging when the system was solely adopted. Opening all the windows was verified to provide reliable radon reduction in a short time, and bidirectional ventilation was determined to be more effective than unidirectional ventilation. Although sealed conditions can be affected by external ventilation, the reduction rate was $60 \%$ or 
below. Therefore, it was verified that, in general, partial ventilation was significantly more effective for indoor radon management.

Radon reduction by mechanical ventilation with a relatively low operational intensity was more effective in small spaces, while that with a relatively high intensity of mechanical ventilation was more effective in large spaces. Therefore, it is considered necessary to ventilate with a mechanical ventilation intensity that matches the properties of the space or a ventilation system that combines natural and mechanical ventilation to predict the radon reduction effect of mechanical ventilation alone.

Author Contributions: Conceptualization, J.C. and H.H.; methodology, J.C. and H.H.; investigation, J.C. and H.H.; resources, S.K., G.K., B.P. and J.L.; data analysis, J.C.; writing-original draft preparation, J.C.; visualization, J.C.; supervision, E.-M.C. and C.L. All authors have read and agreed to the published version of the manuscript.

Funding: This research received no external funding.

Institutional Review Board Statement: Not applicable.

Informed Consent Statement: Not applicable.

Data Availability Statement: Not applicable.

Acknowledgments: This work was supported by a grant from the National Institute of Environment Research (NIER), funded by the Ministry of Environment (MOE) of the Republic of Korea (NIER2020-01-01-038).

Conflicts of Interest: The authors declare no conflict of interest.

\section{References}

1. Gregory, B.; Philip, P.J. National Radon Results: 1985 to 2003; US Environmental Protection Agency: Washington, DC, USA, 2004.

2. World Health Organization. WHO Handbook on Indoor Radon: A Public Health Perspective; World Health Organization Press: Geneva, Switzerland, 2009.

3. Olsthoorn, B.; Rönnqvist, T.; Lau, C.; Rajasekaran, S.; Persson, T.; Månsson, M.; Balatsky, A.V. Indoor radon exposure and its correlation with the radiometric map of uranium in Sweden. Sci. Total Environ. 2021, 811, 151406. [CrossRef] [PubMed]

4. Calin, M.R.; Ivan, C.; Dragusin, M.; Radulescu, I. Measurement and Assessment of Radon Gas Concentration in IFIN-HH and ELI-NP Using the Active Method. Rom. J. Physics. 2019, 64, 813.

5. United Nations. Sources. Effects and Risks of Ionizing Radiations, United Nations Scientific Committee on the Effects of Atomic Radiation 1988 Report to the General Assembly, with Annexes; United Nations: New York, NY, USA, 1988.

6. International Agency for Research on Cancer. Man-Made Mineral Fibres and Radon; IARC Monographs on the Evaluation of Carcinogenic Risks to Humans, 43; International Agency for Research on Cancer: Lyon, France, 1988.

7. National Research Council. Health Risk of Radon and Other Internally Deposited Alpha Emitters, Report of the Committee on the Biological Effects of Ionizing Radiation (BEIR-IV); National Academy Press: Washington, DC, USA, 1988.

8. UNSCEAR. United Nations Scientific Committee on the Effects of Atomic Radiation, 2000 Report. In Sources and Effects of Ionizing Radiation, UNSCEAR 2000 Report to the General Assembly with Scientific Annexes; United Nations: Vienna, Austria, 2000.

9. Jacobi, W. Lung cancer risk from environmental exposure to radon daughters. ICRP Publication 50. Radiat. Prot. Dosim. 1988, 24, 19-23. [CrossRef]

10. IAQ. Indoor Air Quality. A Citizen's Guide to Radon. Available online: https://abetterlookllc.com/wp-content/uploads/2018/1 1/09e61b3923a5876e2dbe7d181f273056.pdf (accessed on 1 May 2021).

11. United Nations Scientific Committee on the Effects of Atomic Radiation (UNSCEAR). Effects of Ionizing Radiation. Annex E: Sources-to-Effects Assessment for Radon in Homes and Workplaces; United Nations: New York, NY, USA, 2008.

12. Al-Jarallah, M. Radon exhalation from granites used in Saudi Arabia. J. Environ. Radioact. 2001, 53, 91-98. [CrossRef]

13. Saad, A.F.; Abdalla, Y.K.; Hussenin, N.A.; Elyaseery, I.S. Radon exhalation rate from building materials used on the Garyounis University campus, Benghazi, Libya. Turk. J. Eng. Environ. Sci. 2010, 34, 67-74.

14. Cothern, C.R.; Smith, J.E., Jr. Environmental radon. Environ. Sci. Res. 1987, 35, 31-58.

15. Calin, M.R.; Radulescu, I.; Chiper, D.; Barna, C.; Cimpeanu, C. Chemical characterization and radiation exposure from the natural radioactivity in Romanian building materials. Radiochim. Acta 2018, 106, 413-425. [CrossRef]

16. Keller, G.; Hoffmann, B.; Feigenspan, T.H. Radon permeability and radon exhalation of building materials. Sci. Total Environ. 2001, 272, 85-89. [CrossRef]

17. Hong, H.; Choi, J.; Yoon, S.; Kim, H.; Lee, C. Evaluation of the Radon Contribution Rate in Apartments through Evaluation of the Radon Exhalation Rate from Building Materials. J. Environ. Health Sci. 2021, 47, 425-431. [CrossRef] 
18. Chen, J.; Naureen, M.R.; Ibrahim, A.A. Radon exhalation from building materials for decorative use. J. Environ. Radioact. 2010, 101, 317-322. [CrossRef] [PubMed]

19. Rizo-Maestre, C.; Víctor, E.-I. Radon gas in the city of Alicante high risk of low indoor air quality in poorly ventilated buildings. Int. J. Environ. Res. Public Health 2020, 17, 8762. [CrossRef] [PubMed]

20. Collignan, B.; Powaga, E. Impact of ventilation systems and energy savings in a building on the mechanisms governing the indoor radon activity concentration. J. Environ. Radioact. 2017, 196, 268-273. [CrossRef] [PubMed]

21. Choi, J.; Hong, H.; Lee, J.; Yoo, J.; Park, B.; Kim, G.; Yoon, S.; Lee, C. Evaluation of radon concentration according to mechanical ventilation systems in apartments. J. Environ. Health Sci. 2021, 47, 330-338.

22. Ministry of Land Infrastructure and Transport, The National Atlas of Korea I. Available online: http://nationalatlas.ngii.go.kr/ pages/page_525.php (accessed on 16 December 2021). 